\title{
Strength of Material Hap-Borosilicate and Their Sintering Behaviors
}

\author{
BURMAWI ${ }^{1}$, NOVESAR JAMARUN ${ }^{*}$, SYUKRI ARIEF ${ }^{2}$ and GUNAWARMAN ${ }^{3}$ \\ 1'Department of Mechanical Engineering Bung Hatta University, Padang, Indonesia. \\ 2Department of Chemistry Andalas University, Padang Indonesia. \\ ${ }^{3}$ Department of Mechanical Engineering, Andalas University, Padang Indonesia. \\ ${ }^{*}$ Corresponding author E-mail: Novesar@unand.ac.id
}

http://dx.doi.org/10.13005/ojc/330242

(Received: February 03, 2017; Accepted: March 26, 2017)

\begin{abstract}
The high strength of hydroxyapatite is required for biomedical applications . Silicon (Si) and Boron $(\mathrm{Br})$ are added to get a higher strength material. The mixing process HAp, Si and $\mathrm{Br}$ is done by ball milling. This process is followed by the compression with the pressure of 70 $\mathrm{kg} / \mathrm{cm} 2$ with comparison $\mathrm{HAp}: \mathrm{Si}, \mathrm{Br}=85: 15,90: 10$ and $95: 5$. Finally the mixture is sintered at temperatures of $1000^{\circ} \mathrm{C}$. The material is characterized by X-Ray Diffraction (XRD). The hardness of their sample is determined by vickers hardness test. The compressive strength is measured by compression universal test machine. The maximum hardness is obtain for composition of $85: 15$ that is 47,3 Vickers Hardness Number (VHN) with maximum compressive strength of 3.48 $\mathrm{MPa}$. So it was concluded that $\mathrm{Si}$ and $\mathrm{Br}$ can be improve the strength of bio composite hydroxyapatite..
\end{abstract}

Keyword: High Strength, Hydroxyapatite, Biokompatible, $\mathrm{Si}, \mathrm{Br}$

\section{INTRODUCTION}

Hydroxyapatite is a material that can be used as a biomedical material. It can also be used as a material implant ${ }^{1}$. This material has similarities with human bones ${ }^{2}$. Hydroxyapatite can be obtained by methods: sol-gel, hydrothermal and precipitation ${ }^{3-6}$

Hydroxyapatite can be produced from bovine bones ${ }^{7-8}$. The powder produced bovine bones are extremely brittle or has a very low strength. The addition material to increase the strength is necessary. The added material used should be of bio medical, biocompatible and do not cause bad influence on the human body. Lots of material can be added to hydroxyapatite include Silica (Si) and Boron (Br). The addition of silica at hidroxyapatite can affect the interaction between the ions, electrostatic and in the strengthening of the compound. Silica at high temperatures can serve as a binder ${ }^{9}$.

The addition of silica ${ }^{10}$ effect on the compressive strength. Boron can only be added should not be more than $5 \%$ for health, especially 
for artificial bone applications ${ }^{11}$. Addition of silica and boron is aiming to create bio composite.

Temperature sintering should be about $1000^{\circ} \mathrm{C}$. Since at temperatures above $1000^{\circ} \mathrm{C}$ can cause structural instability of hydroxyapatite. This process produces tri calcium phosphate ${ }^{12}$.

The Strength of material for the application of biomaterial is very important. The biomaterials is general have lower compressive strength. The compressive strength and hardness can be enhanced with other techniques. Besides, it is necessary to add materials or other minerals that can improve the strength of the bio composite material ${ }^{13}$.

In this research, the material used hydroxyapatite from bovine bone has porosity. The material is formed into bio composite. The addition of Silica and Boron elements as a binder material in the formation of HAp-borosilicate bio composite. The Strength of material is determined with the Vickers hardness and compressive strength.

\section{MATERIAL AND METHOD}

The material used in this research is hydroxyapatite Obtained from bovine bones. Hydroxyapatite mixed with borax acid and silica in the ratio 85: 15: 90: 10 and 95:5. The mixture of materials reviews is constant, HAp: 85, 90 and 95 percent while Boron not more than $5 \mathrm{wt} \%$ remainder is silica.

The substitution of $\mathrm{Si}$ - $\mathrm{Br}$ - HAp was done by using steel ball milling with a speed of 200 rpm for 1 hour, Material that is shaped like a pellet

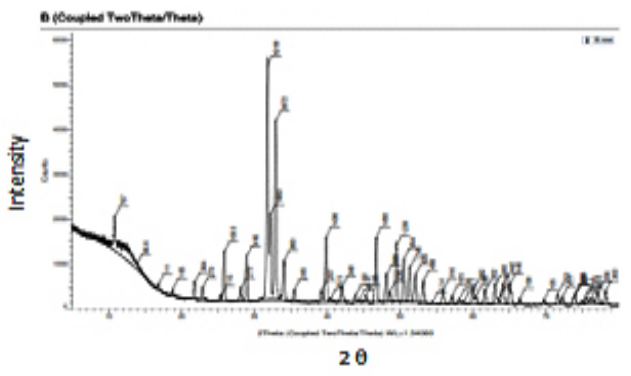

Fig. 1: XRD Pure Hidroxyapatite from bovine bone with a diameter of $10 \mathrm{~mm}$ followed by formation of compacting pressure $70 \mathrm{Kg} / \mathrm{cm} 2$. Sintering conducted at Temperatures of $1000^{\circ} \mathrm{C}$ for 3 hours. Further tested X-ray diffraction (XRD) and mechanical testing that Vickers hardness test and compression test universal testing machine.

\section{RESULTS AND DISCUSSIONS}

\section{XRD}

From the figure 1. seen that the compound hydroxyapatite produce from bovine bones. Meanwhile From XRD peaks seen at figure 2, 3 and 4 the location of hydroxyapatite-borosilicate compound $2 \theta$ of 31.7 and 32.2 with $\mathrm{Cu} \mathrm{K \alpha}$. Silica and boron are not too much influence hydroxyapatite compound ${ }^{14}$. It turned out to silica and boron have subtituted HAp position in the microstructure. Cause when compared with a pure hydroxyapatite, the resulting shape of the curve is very similar.

From the graph of XRD seen difference between figure 1 with figure 2, 3 and 4 . Figure 1 shows the functional groups of hydroxyapatite compound. In figure 2, 3 and 4 looks change with the advent of a new functional group of hydroxyapatiteBorosilicate.

Figure 2, 3 and 4 seen the number of functional groups borosilicate formed. The higher the borosilicate composition, the number of functional groups HAp-Borosilicate is also growing.

$\mathrm{Ca}$ and $\mathrm{P}$ ions can be substituted by ions of silicon and boron. This can be seen in the XRD curve. When compared with the mixing of $\mathrm{HAp}-\mathrm{Si}$, $\mathrm{Mg}^{15}$. It is seen a similar pattern. This is due to the

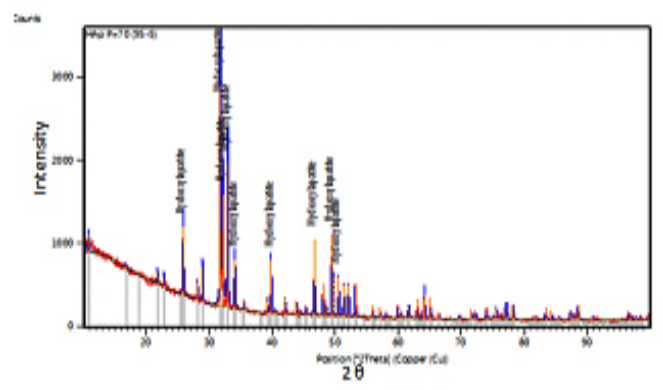

Fig. 2: XRD HAp-Borosilicat, 95:5 
interaction between compounds in hydroxyapatite compound. From the results of XRD analysis of the compounds contained impurities but not affecting the hydroxyapatite compounds in general.

The addition silica to the hydroxyapatite is mixed perfectly (Figures 2, 3 and 4 ) when compared with research Bogya et al., ${ }^{16}$. It is because the element boron followers that give effect to the formation of silica glass.

\section{Hardness test}

Hydroxyapatite before added silica and boron have fragile nature. With the addition of silica and boron increased hardness bio composites. From the figure 5 . it can be seen that a higher composition of silica and boron additions will improve the material's hardness value. Looks at the composition of 85:15 has a hardness of $47.66 \mathrm{VHN}$, the higher the silica composition can increase of the hardness of the material.

The sintering temperature of $1000^{\circ} \mathrm{C}$ to give effect to $\mathrm{HAp}$, $\mathrm{Si}$ and $\mathrm{Br}$ because phase boron temperatures above $950^{\circ} \mathrm{C}$ is liquid phase ${ }^{17}$ and is able to form a bioactive glass ${ }^{18}$. Crystalline HAp provides a fairly low hardness value range between 0.6 and $1.5 \mathrm{MPa}^{19}$. The addition of silica $5 \%$ and $10 \%$ on HAp with a sintering temperature of $1000^{\circ}$ $\mathrm{C}^{19}$ gives the value of the Vickers hardness $111 \mathrm{VHN}$ and $19 \mathrm{VHN}$ but in this research the composition of HAp same turned out to give different hardness, with the addition of the composition of $\mathrm{Si}$ and $\mathrm{Br}, 5 \%$ and $10 \%$ turned out to be an escalation of hardness in the HAp-Borosilicate, this is due to the influence of bioactive borosilicate with a sintering temperature

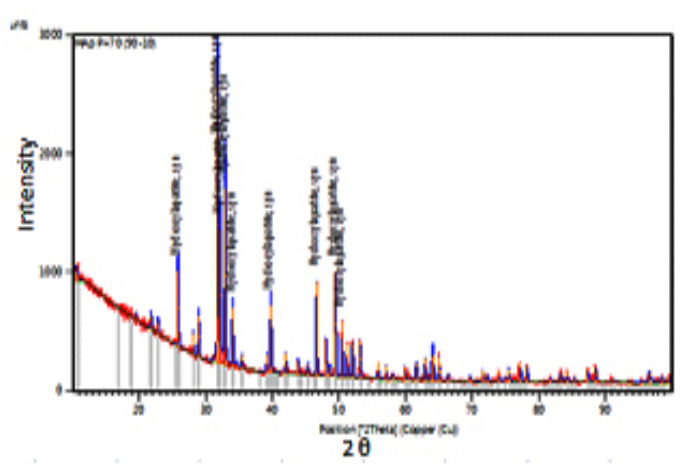

Fig. 3: XRD HAp:Borosilicat, 90 : 10 of $1000^{\circ} \mathrm{C}$ provide vickers hardness values of 28 $\mathrm{HV}$ and $36 \mathrm{HV}$.

In this case an escalation of hardness that is comparable to the increase given borosilicate composition.

\section{Compressive strength}

Silica can serve as a binder to form the HAp-borosilicate bio composites. This affects the compressive strength of the material. From figure 6 the higher the silica and boron composition and generated higher the compressive strengths.

Figure 6 shows the compressive strength values of bio composites HAp-Borosilicate. The maximum value is $3.48 \mathrm{GPa}$. It is lower in comparison with $\mathrm{HAp}-\mathrm{Al} 2 \mathrm{O} 3$ with $\mathrm{CIG}$, but has low porosity shortages value with the increasing sintering temperature and decreasing with adding composition $^{20}$.

From the graph of an increase in compressive strength follows the curves correspond to the addition of borosilicate

The hardness and compressive strength are visible. Affects hydroxyapatite material composition of compounds that have been substituted by $\mathrm{Si}$ and $\mathrm{Br}$. The forming is done by compacting with a pressure of $70 \mathrm{~kg} / \mathrm{cm} 2$ and at a temperature sintering at $1000{ }^{\circ} \mathrm{C}$ Showed a Considerable effect on strengths of materials significant.

The Compressive strength of materials is increases with the addition of material Silica (Si) and Boron $(\mathrm{Br})$. When compared with pellet

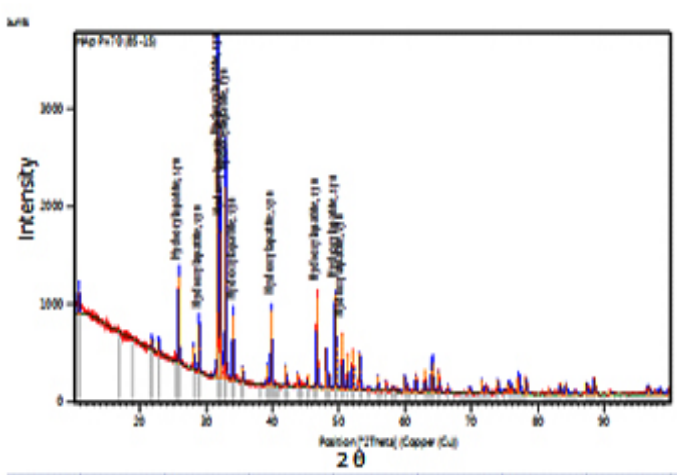

Fig. 4: XRD HAp- Borosilicat, 85 : 15 


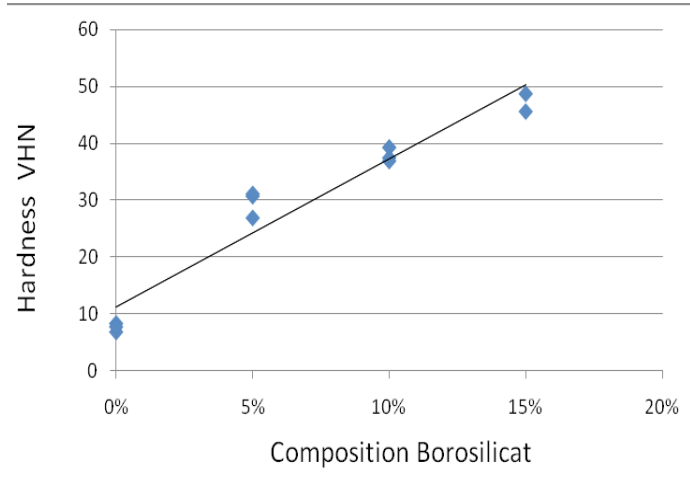

Fig. 5: Hardness HAp-Borosilicate

hydroxyapatite produce with a pressure of $150 \mathrm{~kg} /$ $\mathrm{cm}^{2}$ turned out to be very fragile. HAp-Borosilicate turns giving considerable increase compressive strength significant against ${ }^{21}$.

Likewise, the value of the compressive strength of the composite $\mathrm{HAp}, \mathrm{Si}, \mathrm{Br}$ turns compositions also Affect the value of the compressive strength of the material. In this case the amount of silica and Boron can Increase the value of the compressive strength of the mixture $\mathrm{HAp}$ and $\mathrm{Si}$, $\mathrm{Br}$.

\section{CONCLUSION}

From the above result hydroxyapatite material substitution by $\mathrm{Si}$ and $\mathrm{Br}$, however, the

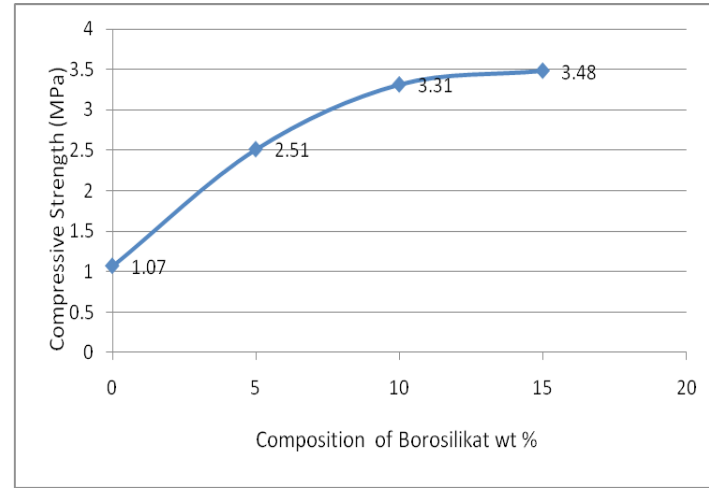

Fig. 6: Compressive Strength HApBorosilicate

number of $\mathrm{Si}$ and $\mathrm{Br}$ composition can affect the hardness and compressive strength value of the material.

The addition of silica and boron material can improve material hardness and compressive strength bio composite HAp-Borosilicate. Likewise factor mold pressure and temperature sintering .

\section{ACKNOWLEDGMENTS}

Thanks the author to convey to the Indonesian government, especially Research and Technology Department and Higher Education, which has funded this research.

\section{REFFERENCES}

1. Nayak, A K.: Bio nano composite, International journal of ChemTech Research,:2010,2,903907.

2. VS Orlovski.:V.S.Komlev and SM Burian.: Biomaterial.: 2002, 1139-1172

3. Sari.T,P:JamarunN,:Syukri,:Azharman Z.:As regiA.: Orient.J.Chem.,2014,30,1799-1804

4. BingolO.R and Durucan C.: Americ.J.Bio Sci., 2012,4,50-59

5. Eslami H.:Solati-Hashjin M.T.: reza M.: Iran J.Pharm.Sci., 2008,4, 127-134

6. Jamarun.N.:Zefri A.:Syukri A.:Tika P.S.: Asregi A.: Elvina S.: Rasayan J.Chem.,2015,8

7. Davids grennspand.: Comparison of $A$ synthetic and Bovine Derived hydroxyapatite Bone Graft Substitute, 2012.

8. Singh Anjuvan, Bull Material Science 2012 .,35(6), 1031 - 1038.

9. Vandiver ,J.: Delphine Dean.: Nelesh P.; Claudia B., Interscience.

10. El Yacoubi.A.:A Masit.: M Fathi.B.: Chafic El Idrisi.: K Yamni.: IOSR Journal of Applied Chemistry. 2011, 7, 24-29

11. Deliormanli AM.: Sciverse Science Direct, 2012, 32, 3637- 3646.

12. Kim. S.R.: J.H. Lee.: Y.T.Kim.: D.H.Riu.: S.J.Jung.: Y.J.Lee.: S.C.Chung, Elsevier, Biomaterial, 2003, 24, 1389-1396. 
13. Nakata,K,; Takhasi Kubo,:Chiya Numako,:Takamasa Onoki,:Atsusi Nakahina, Material Transaction, 2009, 50, 1046-1049

14. E.S.Bogya.;R.Barabas.:L.Bizo.:V.R. Dejeu. .Ecer Confrence, 2009

15. B.Cicek,;A.Tucci.;E.Bernardo.;J. Will.;A.R.Boccani. Elsevier, 2014, 60456051.

16. Roger.F.Brown.; Mohamed.N.Raha man.;Agatha.B.Dwilewicz.; Wenhai. Huang.;Delbert.E.Day.;Yadong Li.;B.Sonny Bal. Wiley Periodicals Inc, 2008.

17. B.Viswanath.;R.Raghavan.;U.Ramamurty and N.Ravishankar, Elsevier, science direct, 2007 361-364.
18. B.Bulut.;N.Demirol.;Z.E.Erkmen.;E.S.Kayali, Acta Physica Polonica, 2015, 127

19. Faik Nuzhet Oktar.;Simon Agathopoulos.;L. Sergi Ozyegin.; Oguzhan Gunduz.;Nermin Demirkol.;Yahya Bozkurt.;Serdar Salman, J, Mater Science Med,DOI 10.1007/s 10856007-3200-9

20. B.Viswanath.:R.Raghavan.:U.Rumamurty and N.Ravishankar. Elsevier.Science Direct Scripta Materialia,2007. 57, 361-364

21. E.Hosseinzadeh.:M.Davarpanah.;N. Hassanzadeh.;S.A.Tavakoh., International Journal of Organ Transpalntation Medicine, 2011 